Современное образование

DOI https://doi.org/10.24866/VVSU/2073-3984/2021-2/120-129

УДК 378

\author{
А.А. Компаниец \\ Дальневосточный федеральный университет \\ Владивосток. Россия
}

\title{
О необходимости формирования цифровой компетентности у современного педагога как субъекта цифрового образовательного пространства
}

В XXI веке одним из центральных трендов в образовании является цифровизация образовательного процесса. Современному педагогу как непосредственному участнику цифровизации образования, как субъекту цифрового образовательного пространства следует понимать содержание основных категорий цифрового образовательного пространства. В частности, активное использование цифровых технологий и трансформирующиеся в связи с этим образовательные технологии приводят к пониманию необходимости формирования у современного педагога способности уверенно, эффективно, безопасно, критично, творчески и этично выбирать и применять цифровые технологии в своей профессиональной деятельности. В данной статье в широком понимании предложено содержание цифрового образовательного пространства. Представлен авторский взгляд на содержание феномена «цифровая компетентность педагога» в обозначенной структуре цифрового образовательного пространства. Рассмотрены две модели цифровой компетентности (Г.У. Солдатова, Joint Research Centre (JRC), the European Commission's science and knowledge service). На основе обозначенных моделей цифровой компетентности предложен список актуальных цифровых компетенций, отражающих способность решать задачи из сфер контента, коммуникации и сотрудничества, обеспечения безопасности, решения технических проблем, потребления и технологических решений средствами цифровых инструментов. Проанализированы результаты анкетирования, проведенного среди учителей, преподавателей, студентов-бакалавров педагогического вуза как субъектов цифрового образовательного пространства. Выявлена заинтересованность респондентов в необходимости формирования цифровой компетентности в вопросах достоверного поиска информации, создания цифрового контента, организации онлайн-коммуникации и сотрудничества, обеспечения безопасности личных данных и устройств в сети Интернет. Выявлен «проблемный» компонент цифровой компетентности (организация безопасной деятельности в сети Интернет), на который следует обратить особое внимание при формировании цифровой компетентности у современного педагога на начальном этапе обращения к цифровому образовательному пространству.

Компаниец Алина Александровна - аспирант; e-mail: mail_boxx_2006@mail.ru 120 
Ключевые слова и словосочетания: цифровизация образования, цифровое образовательное пространство, цифровая компетентность, модель цифровой компетентности, компонент цифровой компетентности, цифровые компетенции.

\title{
A.A. Kompaniets
}

Far Eastern Federal University

Vladivostok. Russia

\section{On the need for the formation of digital competence in the modern teacher as a subject of the digital educational space}

\begin{abstract}
In the XXI century, one of the central trends in education is the digitalization of the educational process. A modern teacher, as a direct participant in the digitalization of education, as a subject of the digital educational space, should understand the content of the main categories of the digital educational space. In particular, the active use of digital technologies, and the educational technologies that are being transformed in this regard, lead to an understanding of the need for the modern teacher to develop the ability to confidently, effectively, safely, critically, creatively and ethically choose and apply digital technologies in their professional activities. In this article, in a broad generalized sense, the content of the digital educational space is proposed. The author's view on the content of the phenomenon "digital competence of the teacher" in the designated structure of the digital educational space is presented. Two models of digital competence are considered (G. U. Soldatova, Joint Research Centre (JRC), the European Commission's science and knowledge service). Based on the identified models of digital competence, a list of relevant digital competencies is formulated, reflecting the ability to solve problems in the areas of content, communication and cooperation, security, technical problem solving, consumption and technological solutions by means of digital tools. The results of a survey conducted among teachers, teachers, and undergraduate students of a pedagogical university as subjects of the digital educational space are analyzed. The respondents ' interest in the need to develop digital competence in the issues of reliable information search, creation of digital content, organization of online communication and cooperation, ensuring the security of personal data and devices on the Internet was revealed. The "problematic" component of digital competence (organization of safe activities on the Internet) is identified, which should be paid special attention to when forming digital competence in a modern teacher at the initial stage of turning to the digital educational space.
\end{abstract}

Keywords: digitalization of education, digital educational space, digital competence, digital competence model, digital competence component, digital competencies.

\section{Введение}

В настоящее время в мировом масштабе можно наблюдать активное формирование глобальной среды международной коммуникации, цифровизацию экономической и социальной жизни общества. Все эти процессы свидетельствуют о том, что глобальный мир начала XXI века проходит этап трансформации исторического масштаба, одним из важных направлений которой является цифровизация в сфере образования. 
На сегодняшний день можно утверждать, что педагоги общеобразовательных организаций, вузов, а также недавние выпускники педагогических вузов не вполне компетентны в вопросах организации эффективной цифровизации школьного образования, продуктивного применения цифровых технологий. Об этом свидетельствовали многочисленные проблемные ситуации, возникшие в нашей стране в связи с переходом на дистанционное обучение в марте 2020 года. Таким образом, остро стоит вопрос о формировании у педагогов компетентности, позволяющей им эффективно осуществлять педагогический процесс в условиях цифровизации образования. При этом возникает ряд вопросов: Какой именно компетентностью должен обладать педагог, чтобы быть полноценным субъектом цифровой трансформации школьного образовательного процесса? Какими цифровыми умениями и навыками следует обладать педагогу, чтобы в ходе осуществляемого им процесса обучения каждый обучаемый овладел компетенциями XXI века (критическим мышлением, способностью к самообучению, умением полноценно использовать цифровые инструменты, источники и сервисы в своей повседневной работе) и мог творчески применять имеющиеся знания в быстро развивающейся цифровой среде? Другими словами, речь уже идет не о простом доступе к ИКТ-технологиям и их использовании, а о способности извлекать из них значительную пользу для работы, учебы, жизни.

Предмет исследования - цифровая компетентность современного педагога как субъекта цифрового образовательного пространства.

\section{Основная часть}

Сравнительно недавно в отечественной научной литературе появился новый термин «цифровая компетентность», вызывающий интерес исследователей в связи с процессами цифровизации образования, происходящими в нашей стране. Однако на данный момент в России существует достаточно ограниченное количество исследований по данной теме (Г.У. Солдатова, Е.И. Рассказова). Более детально этот вопрос освещен современными зарубежными исследователями (Center for Digital Dannelse; R. Justenhoven; Joint Research Centre (JRC), the European Commission's science and knowledge service). Анализ тематических исследований отечественных и западных авторов показывает, что понимание содержания феномена «цифровая компетентность» весьма разнообразно и пока не существует общего или согласованного мнения по поводу однозначности его определения.

Конкретизируем определение цифровой компетентности, предложенное авторами Г.У. Солдатовой и Е.И. Рассказовой применительно к педагогу, опираясь на идею непосредственной взаимосвязи цифровой компетентности:

- с цифровыми компетенциями, составляющими цифровой грамотности фундамента для цифровой компетентности, которые при грамотном овладении, систематизации, постоянном развитии и совершенствовании будут в системе формировать цифровую компетентность;

- с цифровыми технологиями как первоопределяющим элементом для формирования цифровой компетентности (рис. 1) [1;2]. 


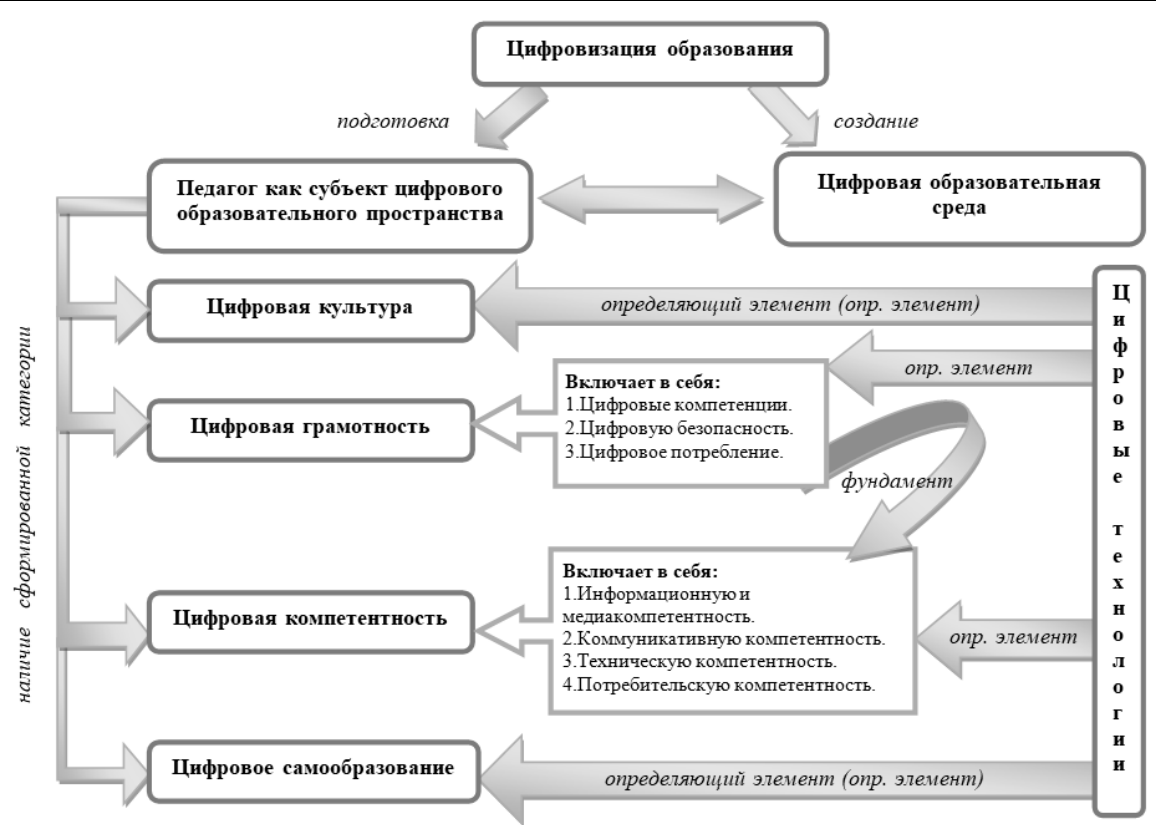

Рис. 1. Содержание цифрового образовательного пространства

Таким образом, под цифровой компетентностью педагога будем понимать способность личности, основанную на непрерывном овладении цифровыми компетенциями, уверенно, эффективно, безопасно, критично, творчески и этично выбирать и применять цифровые технологии в разных сферах профессиональной деятельности, а также готовность к такой деятельности. Рассмотрим наиболее упоминаемые в научных литературных источниках отечественную и западную модели формирования цифровой компетентности.

В отечественной модели цифровой компетентности, предложенной Г.У. Солдатовой и Е.И. Рассказовой, в структуре цифровой компетентности выделены четыре компонента: 1) информационная и медиакомпетентность; 2) коммуникативная компетентность; 3) техническая компетентность; 4) потребительская компетентность [2].

Западная модель цифровой компетентности EU Digital Competence Framework, предложенная исследователями центра Joint Research Centre [4], представлена цифровыми компетенциями по пяти областям: 1) цифровые компетенции в сфере контента; 2) цифровые компетенции в сфере коммуникации и сотрудничества; 3) цифровые компетенции в сфере обеспечения безопасности; 4) цифровые компетенции в сфере решения технических проблем; 5) цифровые компетенции в сфере потребления и технологических решений средствами цифровых инструментов.

Можно заметить, что обе модели во многом схожи по составу компонентов, образующих цифровую компетентность, и могут взаимно дополнять друг друга. Под компонентом цифровой компетентности будем понимать соответствующие 
цифровые компетенции, позволяющие в совокупности эффективно решать поставленные задачи и получать требуемый результат, определяемый смысловым и функциональным содержанием данного компонента. Проанализировав содержание компонентов цифровой компетентности вышеописанных отечественной и западной моделей цифровой компетентности, в обобщенном виде выделим следующие группы цифровых компетенций, которые, на наш взгляд, должны быть сформированы у современного педагога:

- цифровые компетенции, связанные с достоверным поиском, пониманием, организацией, архивированием цифровой информации, ее критическим осмыслением;

- цифровые компетенции для создания образовательных материалов и их совместного использования;

- цифровые компетенции, необходимые для сотрудничества, онлайнкоммуникации в различных формах (веб-конференции, вебинары, электронная почта, чаты, блоги, форумы, социальные сети и др.);

- цифровые компетенции, необходимые для организации безопасной деятельности в сети Интернет (обеспечение безопасности данных и устройств в сети Интернет);

- цифровые компетенции, позволяющие решать с помощью компьютера повседневные задачи, предполагающие удовлетворение различных цифровых потребностей;

- цифровые компетенции, позволяющие эффективно и безопасно использовать компьютер и соответствующее ПО для решения различных технических цифровых задач.

Формирование каждой из обозначенных цифровых компетенций невозможно без освоения и уверенного владения соответствующими инструментами цифровыми технологиями. Так, F. Pettersson [3] полагает, что основу цифровых компетенций составляют умение, возможность и способность грамотно и эффективно использовать цифровые инструменты для решения поставленных задач. Данное понимание особенно актуально в сфере образования, поскольку сегодня цифровые технологии становятся центральной частью повседневной работы педагогических работников. Педагоги вынуждены переосмысливать и трансформировать предыдущие образовательные традиции с помощью современных цифровых технологий. Ввиду этих проблем, по мнению F. Pettersson, предъявляются значительные требования к образовательным учреждениям относительно разработки стратегий для формирования и поддержки цифровых компетенций, необходимых для обеспечения высокого качества преподавания и обучения [3]. Возможными вариантами формирования/повышения уровня сформированности цифровой компетентности у современных педагогов нам представляется подготовка/переподготовка педагогов в рамках курсов повышения квалификации, тематических семинаров, вебинаров. 


\section{Методология и методы исследования}

В процессе работы использованы методы теоретического анализа, обобщения, конкретизации и классификации информации научно-педагогического характера.

Цель исследования - выявление личного отношения к проблеме формирования цифровой компетентности у современного педагога, а также оценка уровня заинтересованности тематическими семинарами, посвященными вопросам цифровизации образовательного процесса.

В марте-мае 2021 года нами было проведено анкетирование среди учителей-предметников Приморского края. В анкетировании приняли участие тринадцать слушателей, прошедших обучение в Центре профессионального развития работников образования Школы педагогики ДВФУ по особенностям использования цифровых ресурсов в деятельности педагога и организации работы педагога в условиях цифровой образовательной среды.

\section{Результаты исследования}

Выявлено, что необходимыми цифровыми компетенциями для современного педагога, по мнению респондентов, являются:

- цифровые компетенции для создания образовательных материалов и их совместного использования - $92 \%$ опрошенных;

- цифровые компетенции, связанные с поиском, пониманием, организацией, архивированием достоверной цифровой информации, ее критическим осмыслением, $-85 \%$ опрошенных;

- цифровые компетенции, необходимые для сотрудничества, онлайнкоммуникации в различных формах (веб-конференции, вебинары, электронная почта, чаты, блоги, форумы, социальные сети и др.), - 77\% опрошенных (рис. 2).

Причем цифровые компетенции, связанные с созданием цифрового контента, наиболее востребованы.

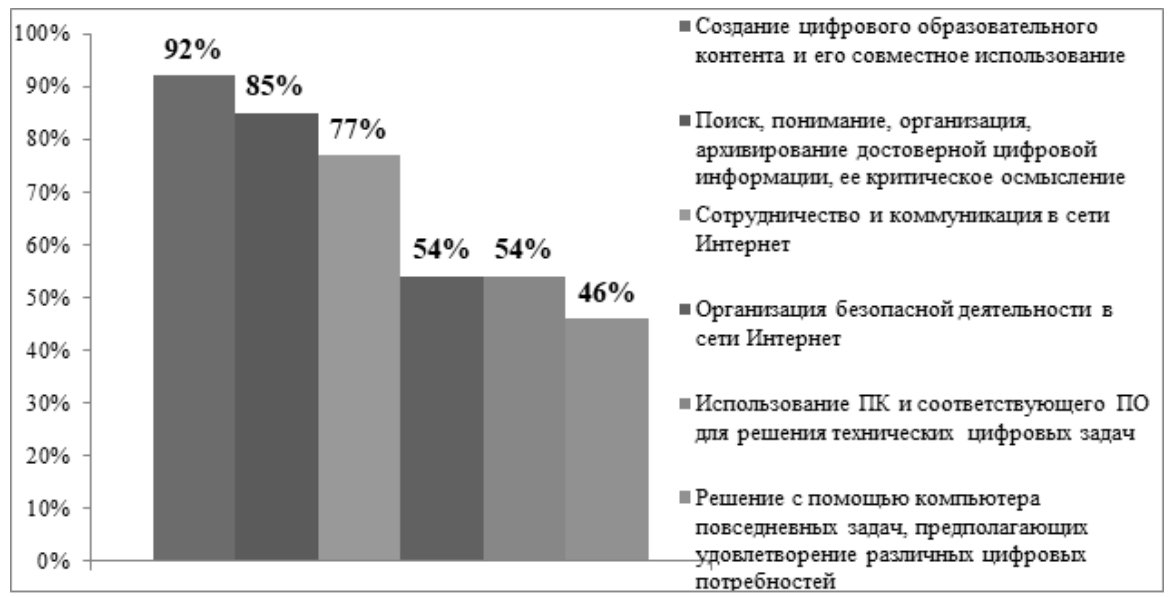

Рис. 2. Сферы профессиональной деятельности, в которых требуется формирование соответствующих цифровых компетенций 
На вопрос о наличии у самих респондентов этого же набора сформированных цифровых компетенций были получены следующие результаты их самооценки: в большей степени респонденты оценивают уровень сформированности у них:

- цифровых компетенций, необходимых для сотрудничества, онлайнкоммуникации в различных формах (веб-конференции, вебинары, электронная почта, чаты, блоги, форумы, социальные сети и др.), - 77\% опрошенных;

- цифровых компетенций для создания образовательных материалов и их совместного использования - $69 \%$ опрошенных;

- цифровых компетенций, связанных с поиском, пониманием, организацией, архивированием достоверной цифровой информации, ее критическим осмыслением, $-69 \%$ опрошенных (рис. 3).

Причем наибольшее количество опрошенных учителей отмечают сформированность у них цифровых компетенций, необходимых для сотрудничества, онлайн-коммуникации.

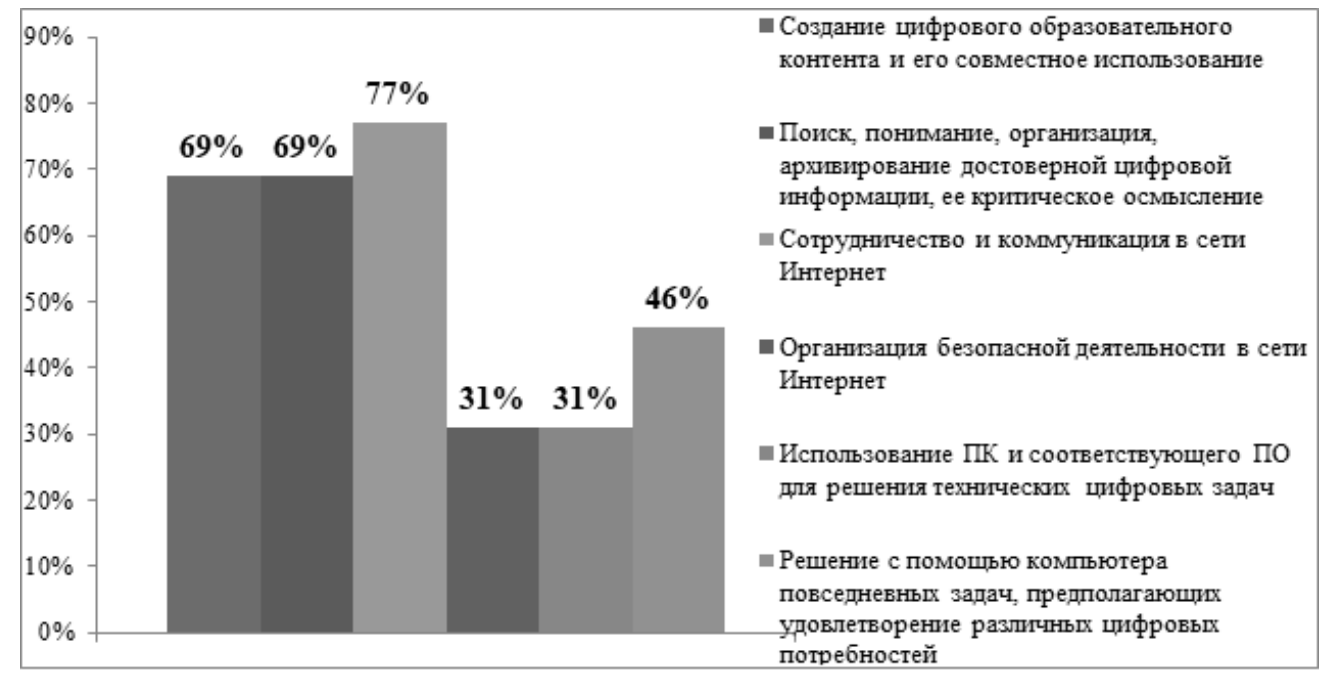

Рис. 3. Уровень сформированности цифровых компетенций по сферам педагогической деятельности

Несмотря на то, что у большинства респондентов, по их мнению, развиты цифровые компетенции создания цифрового образовательного контента и поиска достоверной информации, они все равно хотели бы продолжить совершенствование этих групп цифровых компетенций и достичь более высокого уровня их сформированности - 54\% опрошенных (рис. 4). 
А.А. Компаниец. О необходимости формирования цифровой компетентности...

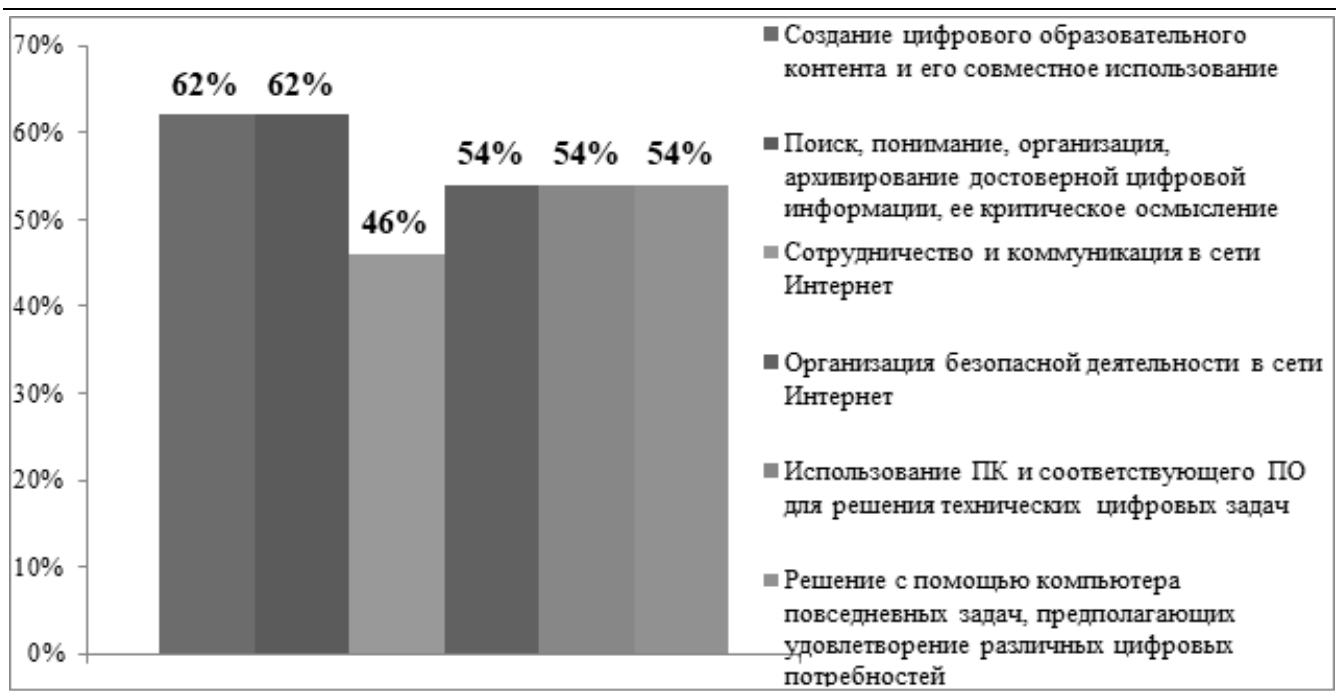

Рис. 4. Сферы профессиональной деятельности, вызывающие заинтересованность в повышении уровня цифровой компетентности

Следует заметить некоторую «непопулярность» вопросов, касающихся обеспечения безопасной деятельности в сети Интернет, а именно: безопасной работы с данными, устройствами в сети Интернет, сохранения авторских прав своих работ, организации безопасного, грамотного и корректного взаимодействия в сети Интернет как самих педагогов, так и их учеников. На наш взгляд, данный компонент цифровой компетентности, наоборот, является одним из важных и необходимых на начальном этапе обращения к цифровому образовательному пространству. Как показывает опыт проведения тематических семинаров и курсов повышения квалификации, разбор кейсов, практических задач, иллюстрирующих реальные проблемные ситуации в сфере обеспечения безопасности, меняет мнение слушателей относительно важности и нужности соблюдения безопасности в сети Интернет. Такими наиболее актуальными примерами являются описание и решение проблемных ситуаций, связанных с нарушением сохранения авторских прав своих работ, с утечкой личных данных педагога, с кибербуллингом учеников.

\section{Выводы и научная новизна}

В педагогическом сообществе все более очевидна тенденция к формированию/совершенствованию компетенций, обеспечивающих эффективное, ответственное, мотивированное, безопасное решение педагогических задач средствами современных технологий в условиях открытой цифровой образовательной среды.

Научная новизна данной статьи состоит в самой постановке проблемы и заключается в том, что исследование направлено на рассмотрение феномена «цифровая компетентность» применительно к педагогу, конкретизацию компонентов цифровой компетентности, которые необходимы для формирования / совершенствования у современного педагога с целью эффективной реализации им профессиональной деятельности. Результаты анкетирования, представленного в 
данной статье, и отзывы слушателей проводимых нами семинаров и курсов повышения квалификации, направленных на формирование цифровой компетентности педагога, приводят к пониманию необходимости формирования / совершенствования каждого компонента цифровой компетентности. Особое внимание необходимо обратить на формирование компонента цифровой компетентности, отвечающего за организацию безопасной деятельности в сети Интернет.

На наш взгляд, формирование компонентов цифровой компетентности, описанных в данной статье, должно входить в обязательную подготовку / переподготовку / повышение квалификации учителей и преподавателей любого вуза как актуальная задача по успешному их вхождению в цифровое образовательное пространство.

Результаты теоретических и практических исследований, отраженные в данной статье, представляют интерес для исследователей проблемы формирования цифровой компетентности педагога, преподавателей педагогических вузов, педагогов-практиков, администрации образовательных организаций, находящихся в поиске стратегии повышения уровня цифровой компетентности своего педагогического коллектива.

1. Компаниец А.А. Приоритеты российского образования: современный учитель как субъект цифрового образовательного пространства. - Текст: электронный // Сетевое образовательное взаимодействие в подготовке педагога информационного общества: сборник статей Международной научно-практической конференции (г. Владивосток, 25-26 октября 2019 г.) / Дальневосточный федеральный университет, Школа искусств и гуманитарных наук. - Владивосток: Изд-во Дальневост. федер. ун-та, 2019. - C. 256-266.

2. Солдатова Г.У., Рассказова Е.И. Модели цифровой компетентности и деятельность российских подростков онлайн. - Текст: электронный // Национальный психологический журнал. - 2016. - №2(22) // Научная электронная библиотека «КиберЛенинка»: [сайт]. - URL: https://cyberleninka.ru/article/n/modeli-tsifrovoy-kompetentnosti-ideyatelnost-rossiyskih-podrostkov-onlayn (дата обращения: 20.05.2021).

3. Pettersson F. On the issues of digital competence in educational contexts - a review of literature. Education and Information Technologies, 2017.- URL: https://doi.org/10.1007/s10639-017-9649-3 (дата обращения: 20.05.2021).

4. The Digital Competence Framework 2.0 // The European Commission's science and knowledge service, 2019. - URL: https://ec.europa.eu/jrc/en/digcomp/digital-competenceframework (дата обращения: 20.05.2021).

\section{Транслитерация}

1. Kompaniec A.A. Prioritety rossijskogo obrazovaniya: sovremennyj uchitel' kak sub"ekt cifrovogo obrazovatel'nogo prostranstva. - Tekst: elektronnyj // Setevoe obrazovatel'noe vzaimodejstvie $\mathrm{v}$ podgotovke pedagoga informacionnogo obshchestva: sbornik statej Mezhdunarodnoj nauchno-prakticheskoj konferencii (g. Vladivostok, 25-26 oktyabrya 2019 g.) / Dal'nevostochnyj federal'nyj universitet, Shkola iskusstv i gumanitarnyh nauk. Vladivostok: Izd-vo Dal'nevost. feder. un-ta, 2019. - S. 256-266.

2. Soldatova G.U., Rasskazova E.I. Modeli cifrovoj kompetentnosti i deyatel'nost' rossijskih podrostkov onlajn. - Tekst: elektronnyj // Nacional'nyj psihologicheskij zhurnal. - 2016. №2(22) // Nauchnaya elektronnaya biblioteka «KiberLeninka»: [sajt]. - URL: 
https://cyberleninka.ru/article/n/modeli-tsifrovoy-kompetentnosti-i-deyatelnost-rossiyskihpodrostkov-onlayn (data obrashcheniya: 20.05.2021).

() А. А. Компаниец, 2021

Для цитирования: Компаниец А. А. О необходимости формирования цифровой компетентности у современного педагога как субъекта цифрового образовательного пространства // Территория новых возможностей. Вестник Владивостокского государственного университета экономики и сервиса. - 2021. - Т. 13, № 2. - С. 120-129.

For citation: Kompaniets A. A. On the need for the formation of digital competence in the modern teacher as a subject of the digital educational space, The Territory of New Opportunities. The Herald of Vladivostok State University of Economics and Service, 2021, Vol. 13, № 2, pp. 120-129.

DOI https://doi.org/10.24866/VVSU/2073-3984/2021-2/120-129

Дата поступления: 22.05.2021. 